\title{
Uma definição biológica do crime $(1933)^{*}$
}

\author{
Dyonélio Machado
}

\section{Delimitação da questão}

O primeiro dever, diante de um assunto da vastidão e complexidade deste que constitui o objeto da presente dissertação, o cuidado mais elementar consiste em proceder a uma delimitação da questão, restringir tanto quanto possível o campo de observação e de estudo. O ponto visado beneficiar-se-á com essa projeção da análise num só foco. Esse trabalho redutor há de ser executado de tal maneira, porém, que a especialização que é o seu objetivo não venha prejudicar de nenhum modo as conclusões gerais a que porventura nos possa conduzir, com as restrições impostas de resto a esse gênero de pesquisas, a nossa investigação científica.

De preferência a um estudo global sobre os caracteres comuns a todos os delitos, adotamos o critério de concentrar as

* Texto originalmente publicado como introdução à edição de 1933 da tese de especialização em psiquiatria intitulada Uma definição biológica do crime. Transcrição e revisão do texto realizada por Francis Moraes de Almeida. Todas as notas foram mantidas na seqüência original. Nas passagens em que o autor traduz textos estrangeiros mantendo a passagem no idioma original manteve-se apenas o texto em português (N. do R.). 
nossas pesquisas sobre uma espécie apenas de infração, espécie, todavia, que inteiramente se prestasse às generalizações em vista, muito embora sejamos o primeiro a reconhecer a precariedade das conclusões em geral, particularmente em criminologia.

Qual, pois, o delito preenchendo todas essas condições? Escolhemos sem titubear, como se vai ver, aquele que, pelas suas conseqüências, constitui, segundo as idéias humanitárias do século, a maior infração cometida contra a organização social: o homicídio.

Não nos achamos sob o império exclusivo da religião, num estado teocrático, onde é o crime de heresia e de sacrilégio que ocupa o primeiro lugar; ${ }^{1}$ nem num estado comerciante apenas, para o qual nenhum delito sobreexcede o delito de fraude; nem no estado militar, onde o primeiro crime é a indisciplina; nem no estado absoluto, no qual o crime de lesa-majestade absorve todos os demais. ${ }^{2}$ Vivemos, como jamais, uma verdadeira vida em sociedade, produto último do esforço de organização do homem, que exatamente repousa sobre o respeito da vida do seu próximo, cujo valor, como observa Joly, está, por assim dizer, "em alta". ${ }^{3}$

A palavra crime, pois, no texto representa originariamente o crime capital, o assassínio. É a sua evolução e a sua gênese que pretendemos traçar nas páginas que se vão seguir.

\section{O homicídio e o seu conceito através da evolução natural do crime}

A morte de um homem praticada por um outro homem - o homicídio traz em si, segundo o critério dominante, um caráter de antinaturalidade que constitui o seu aspecto criminoso. ${ }^{4}$

Esse cunho de antinaturalidade, elemento indispensável para que se verifique o delito, deriva do fato de pertencerem um e outro, a vítima e o agente, à mesma espécie animal. Com efeito, “matar para viver é lei férrea, que domina o mundo dos seres vivos: é uma lei natural e, portanto eminentemente moral, quando se

1. A. Prins. Ciência Penal e Direito Positivo. Trad. do Dr. H. de Carvalho. Lisboa: Livr. Class. Ed., 1915. p. 86.

2. Idem.

3. Henri Joly. Le crime. Étude sociale. Troisième édition. Paris: L. Cerf, s/d. p. 10.

4. Enrico Ferri. L'Omicida nella psicologia e nella psicopatologia criminale. Seconda edizione riveduta ed aumentata. Torino: Un. Tip. Tor., 1925. p. 5. 
mantenha nos limites da natureza (...). Todos os indivíduos das espécies superiores matam os de espécie inferior para com eles se nutrir, e então o ato de matar é plenamente natural e moral; os animais vivem de plantas (...); os animais superiores vivem de animais inferiores; o homem vive de animais e de plantas, e para viver ele mata. - Mas o ato de matar torna-se antinatural quando 'matador e vítima pertençam à mesma espécie"”. ${ }^{5}$

Não é possível estudar o crime como fenômeno privativo da espécie humana, pertencendo-lhe propriamente e, portanto, inteiramente desconhecido dos outros animais. Ele constitui, entre os homens, simplesmente a cópia e reprodução de uma manifestação que vem de trás, que se vem encadeando ao longo de toda a série zoológica. Foi o que reconheceram, entre vários outros, explícita ou implicitamente, Houzeau, ${ }^{6}$ Espinas, ${ }^{7}$ Cognetti, ${ }^{8}$ Lombroso, ${ }^{9}$ Lacassagne, ${ }^{10}$ Trogel, ${ }^{11}$ e sobretudo Ferri, que, sobre a questão, nos deu com efeito uma síntese definitiva. ${ }^{12}$

Segundo ele, a atividade criminosa do homem outra coisa não representa senão uma reprodução e um maior desenvolvimento da criminalidade animal, ${ }^{13}$ encontrando-se já, de fato, como se encontra no mundo animal, na grande variedade dos seus móveis psicológicos, quase todas as formas do crime de matar, próprias do homem. ${ }^{14}$

Pareceria assumir apenas o aspecto de uma derivação erudita a pesquisa em boa hora levada a efeito pela ciência nessa matéria, se a comprovação dessa filiação não viesse tirar do crime esse caráter pessoal, de maldade, que se lhe reconhecia tão facilmente, para dar-lhe antes o cunho de um fenômeno natural, obedecendo a um princípio de causalidade e subordinando-se às regras gerais da evolução. ${ }^{15}$

A investigação científica, operada sistematicamente, descobre nos animais as mesmas causas que impelem o homem ao sacrifício do seu semelhante: a concorrência vital, assumindo então o delito uma "forma anormal de luta pela

5. Idem.

6. Etudes sur les facultés mentales des animaux comparées a celles de l’homme.

7. Espinas, Des sociétés animales.

8. Le forme primitive nella evoluzione economica.

9. II delito degli animali.

10. Lacassagne, De la criminalité chez les animaux.

11. Trogel, Palestras sobre a psicologia dos animais.

12. Ferri. Oo. cit. Reproduzida em grande parte no Uomo Delinquente, de Lombroso.

13. Ferri. Op. cit., 9.

14. Idem.

15. Comp. Ferri. Op. cit., 10. 
$\begin{array}{lllllll}R & E & V & I & S & T & A\end{array}$

LATINOAMERICANA

DE PSICOPATO LOGIA

F U N D A M E N T A L

ano IX, n. 4, dez/2006

existência”; ${ }^{16}$ a conquista da fêmea; a ambição política (nos animais representada pelo intuito de obter o comando do rebanho); o império das paixões, com "exagero" ou "perversão" ${ }^{17}$ dos instintos sociais: do amor, do afeto materno, da defesa própria ou da dos indivíduos colocados sob tutela, do sentimento de utilidade comum, do dever de punição; a cobiça; a ingratidão; a guerra; a vingança; a antipatia; o ímpeto de cólera; a maldade; a própria alienação mental,, ${ }^{18}$ representada, entre os animais, por cinco formas clínicas: tendência hereditária, delírio maníaco, ímpeto de medo, demência senil e alcoolismo. ${ }^{19}$

Em todos esses casos, fica comprovado que o delito entre os animais, como no homem, é o efeito de "tendências individuais", não representa o resultado de “um instinto específico e geral”, manifesta-se num ou dois indivíduos dentre cem da mesma espécie, sofre o impulso de vários móveis psicológicos ou patológicos. Mesmo o modo de execução do crime oferece a variedade que se observa entre os delinqüentes humanos: animais existem que empregam a violência, outros a insídia, alguns se contentam com a simples eliminação da vítima, muitos levam a sua ferocidade até a sevícia do cadáver e ao canibalismo. A própria cumplicidade consciente e criminosa entre vários indivíduos de uma mesma espécie animal já foi observada. ${ }^{20}$ Encontram-se, com efeito, verdadeiras associações de malfeitores entre os animais. ${ }^{21}$ Figuier narra o caso de três castores que se associaram para matar um quarto companheiro; e exemplo do mesmo gênero é fornecido por outras espécies, segundo Darwin. ${ }^{22}$ Para completar o quadro, nem falta mesmo a punição, praticada já em gérmen entre animais de um desenvolvimento social mais acentuado, como se verifica entre os símios, segundo o testemunho de Brehm, ou entre as cegonhas, de acordo com o que nos conta Figuier. ${ }^{23}$

Nós constatamos, de fato, conclui Ferri, que, entre os animais como entre os homens, não só existem algumas raças mais inclinadas do que outras à eliminação do próprio semelhante, mas existem indivíduos mais perversos do que outros, e que transmitem aos seus descendentes o instinto sanguinário; e veremos que aquelas eliminações se cometem ou com aberta violência ou com insídia por indivíduos isolados ou por cúmplices associados na intenção criminosa, e são determinadas ou pela concorrência pela vida ou pelo impulso das paixões. ${ }^{24}$

16. Ferri. Op. cit., 9.

17. Idem, 11.

19. Comp. Pierquin, La folie chez les animaux, apud Ferri, op. cit., p. 13.

20. Ferri. Op. cit., 14 e seguintes.

21. Cesare Lombroso, L'uomo delinquente, in rapporto all'anthropologia, alla giurisprudenza ed alle discipline carcerarie. Quinta edizione. Torino: Bocca,editori, 1896. Tomo I, p. 17.

22. Citados por Lombroso, idem, 18-19.

23. Comp. Ferri, loc. cit.; Lombroso, obr. cit., 29-30.

24. P. 9. 
O paralelismo entre o delito animal e o humano mantém-se, no nosso entender, até o momento em que se dá a intercessão da penalidade, como havemos de ver com os necessários detalhes no capítulo segundo, ao tratarmos da noção da criminalidade. Desde esse instante, um novo mecanismo, em nossa opinião, preside a manifestação delinqüente do homem, que introduziu desde aí no aparelho psicológico do "pensamento criminoso" uma alavanca de um outro gênero.

A extraordinária difusão do ato delituoso na série animal colocou-o na mesma fileira com as demais manifestações naturais, quer dizer, como capaz de entrar facilmente na fenomenologia ordinária. Distingue-se dos atos "permitidos" por um caráter arbitrário ("violência privada arbitrária”25), de antinaturalidade, de violência que se exerce contra indivíduos da mesma espécie. Aliás, Camerano, ${ }^{26}$ a nosso ver mais adiantado neste ponto do que os autores do seu tempo, alargalhe o papel na mecânica do mundo natural, pois define o crime como caracterizando todos os atos "que ou contravém diretamente à lei de conservação do indivíduo ou à da conservação da espécie, ou então prejudicam os outros animais sem serem necessários à conservação do indivíduo ou da espécie”. ${ }^{27}$

A superioridade da concepção de Camerano sobre a dos demais autores reside no fato de haver concebido o caráter de "antinaturalidade" fora da eventualidade de pertencerem o matador e a vítima a "uma mesma espécie animal”, circunstância esta que tão pouco se concilia, com efeito, com a verificação de Darwin, quando acentua que a luta pela existência assume maior violência e é mais encarniçada quando se trava entre indivíduos e variedades pertencendo à mesma espécie. ${ }^{28}$

A concorrência vital conduz normalmente o homem à prática da violência. Mesmo o homicídio, quando perpetrado com o objetivo da conservação do indivíduo, recebe uma exculpação quase automática (justificativa da legítima defesa). A apropriação indébita de bens de outrem, se à sua prática o delinqüente é impelido pela necessidade extrema, merece logo uma justificação espontânea. É conhecida a famosa sentença de Magnaud, ${ }^{29}$ decidindo que a fome é própria a arrebatar a todo ser humano uma parte do seu livre arbítrio e enfraquecer nele, numa grande medida, a noção do bem e do mal; e que faltam os verdadeiros caracteres de uma subtração fraudulenta ao ato de se apossar dum pão numa

\section{Cf. Ferri. Op. cit., p. 5.}

26. Camerano, II delitto fra gli animali, Torino, 1883.

27. Apud Ferri. Op. cit., p. 6 (nota).

28. Charles Darwin. L'origine des espèces au moyen de la selection naturelle ou Lutte pour l'existence dans la nature. Traduit sur l'edition anglaise definitive par Ed. Barbier, Paris, Costes, 1921. p. 82.

29. Tribunal de Chateau-Thierry, audiência do dia 4 de março de 1898. 
padaria, quando quem o pratica é uma mãe de família que não come há 36 horas e que vê o seu filho ainda pequeno prestes a cair nas torturas agudas da mesma privação de alimentos. ${ }^{30}$ — É o "estado de necessidade”, reconhecido por mais de um código, entre estes o brasileiro, e que admite sejam lesados interesses lícitos toda vez que só dessa lesão resulte a conjuração do mal que ameaça o indivíduo.

Caracteriza-se o estado de necessidade, observa Galdino Siqueira, pelo conflito de interesses lícitos, cada um dos quais somente pode ser conservado à custa do outro, situação que pode resultar de forças naturais ou de ato humano. Pressupõe, pois, a situação de perigo atual, que somente pode ser removida pela lesão de interesses lícitos de outrem. É exatamente pela iminência de um perigo, que se assemelha ao estado de necessidade à legítima defesa, porquanto nessa há igualmente iminência de um mal, que só pode ser removido mediante ofensa de interesses jurídicos do agressor. ${ }^{31}$

Distingue-se, entretanto, a legítima defesa do estado de necessidade, pela circunstância de que neste último "há conflito de interesses lícitos, direitos ou deveres, entre si, cada um dos quais só pode ser conservado ou cumprido à custa do outro, ao passo que na legítima defesa o conflito é entre interesses lícitos de um lado e ilícitos de outro". ${ }^{32}$ Verificando-se desigualdade de valor entre os interesses lícitos em conflito, como é o caso, o Estado logicamente não poderia ficar estanho à contenda. Se esses direitos que agora entram em luta não podem coexistir no espaço e no tempo, se a conservação de um implica o sacrifício do outro, "é justo que o menor seja sacrificado e o Estado tem o interesse na conservação do bem mais importante”. ${ }^{33}$

$\mathrm{O}$ ato de força, pois, levado mesmo às suas conseqüências extremas (assassínio, roubo) enquadra-se perfeitamente, desde que realize certas condições, na existência legal do homem. É o excesso nesse ato de força, criando uma "forma anormal de luta pela existência”, na frase de Ferri, ${ }^{34}$ que constitui verdadeiramente o crime. Embora inteiramente prontos a perdoar o ladrão que

30. Les Jugements du Président Magnaud. Réunis et commentés par Henri Leyert. Troisième édition. Paris: Stock édit., 1904. p. 15.

31. Direito Penal Brasileiro, segundo o Código Penal mandado executar pelo Decr. n. 847, de 11 de outubro de 1890 e leis que o modificaram ou completaram, elucidados pela doutrina e jurisprudência, por Galdino Siqueira. Vol. I, Parte Geral, 2. edição, correta e aumentada. Rio de Janeiro: Livraria Jacyntho, 1932. p. 434.

32. Galdino Siqueira. Loc. cit.

33. Idem.

34. V. mais acima. 
rouba para comer e em cujo ato reconhecemos um direito natural, reclamado pelas condições elementares da vida humana, como no caso concreto beneficiado pela dialética de Magnaud, não somos nada benevolentes com o especulador abastado que, sem sair contudo dos limites da lei, entesoura à custa do necessitado e leva portanto aquela faculdade a um grau excessivo e, pois, monstruoso, - a esse "exagero" ou a essa "perversão" dos instintos sociais a que alude incidentalmente Ferri. ${ }^{35}$ É que há realmente no crime, como havemos de demonstrar, um exagero da personalidade, a condicionar um excesso da ação.

Tão natural parece essa concepção que por toda a parte a vemos como que a forçar intuitivamente a trama cerrada e artificiosa das várias teorias que se disputam a primazia em matéria penal. Ninguém ignora que a nossa legislação penal é contemporânea ainda, em espírito, da escola clássica. As modernas doutrinas, inspiradas num princípio de humanidade maior, ${ }^{36}$ ainda não fenderam a couraça de que a rotina tem revestido o nosso direito penal. Não se inspira, portanto, em nenhum argumento de ordem biologista a condição de que se mantenha a "proporção" entre a agressão e a reação do agredido para que se verifique a legítima defesa, ${ }^{37}$ ou a condição de que não haja "excesso" no crime mandado executar por superior legítimo, sem o que não gozará o agente da impunidade que lhe assegura a lei. ${ }^{38}$ É, pois, a intuição natural do homem que, por si só, estabelece a boa regra.

Vê-se, do exposto, como a nossa concepção se distancia da escola antropológica, quando consideramos apenas o critério da quantidade para definir o delito, este não sendo realmente outra coisa senão o modo excessivo com que o ser procura realizar a luta pela vida.

Decomponhamos o crime em seus elementos constitutivos e veremos que, à base de todo ato criminal existe sempre uma necessidade. Não é difícil comprovar que, na humanidade primitiva, toda necessidade tendia a satisfazerse, sem outro embargo senão o que resultasse das dificuldades externas de realização material, desde que o homem primitivo não deveu conhecer limites

35. Veja-se a passagem mais acima.

36. Com efeito, a considerar as coisas sob o seu aspecto mais geral, chega-se à conclusão de que o “pensamento” de Lombroso, a sua verdadeira “originalidade” era a noção, biológica e humanitária, da irresponsabilidade. Desejava chegar a ela a qualquer preço. Tanto, que procurou interpretá-la, sucessivamente, por doutrinas diferentes, “inconciliáveis” como notou Garofalo (primeiro a do atavismo, depois a da epilepsia). Tem-se antes a impressão de um propósito deliberado e apriorístico, existindo anteriormente à indução, do que o produto da indução mesma.

37. Código Penal Brasileiro, Art. 34, alínea 3.a. São Paulo: Editor Saraiva.

38. Idem, Art. 28. 
$\begin{array}{lllllll}R & E & V & I & S & T & A\end{array}$

LATINOAMERICANA

DE PSICOPATO LOGIA

F U N D A M E N T A L

ano IX, n. 4, dez/ 2006

psicológicos, ou internos, à satisfação dos seus desejos. A vida em sociedade, restringindo o direito e o arbítrio do indivíduo no interesse do direito do todo, foi que criou tais limites. Está assim estabelecida - e havemos de ver com que violência - a noção do crime, a idéia de infração.

Desde esse momento a inclinação ao ato proibido não passaria de um fenômeno teórico. O delito, porém, sendo de prática corrente, está a indicar que o homem mede o desejo de satisfazer a sua necessidade, com o castigo a merecer, e que confere àquela uma significação e um valor maiores do que o temor da punição ou as penas que terá de suportar para subtrair-se a esta última.

Tem aqui o seu lugar uma reflexão, entretanto. A necessidade será mesmo enorme objetivamente? Todos os ladrões, como a mãe de família julgada pela forma como vimos, levam a efeito o roubo naquelas mesmas circunstâncias, isto é: para evitar mal maior, porque sucumbiam, efetivamente, de fome? Ou, ao contrário, só em sua mente essa necessidade lhes pareceu assim desmesurada? A grande necessidade, real, justifica o crime, não só nos códigos, como na opinião e nos arestos dos juízes, quando esses códigos são omissos. O que caracteriza a ação criminal é exatamente essa desproporção entre a necessidade (o móvel) e o ato. No fundo, a desproporção só é para quem a contempla, pois que só o é objetivamente, não havendo nunca, subjetivamente, desproporção. O criminoso julga a sua necessidade sempre superior a todos os riscos. ${ }^{39}$

Daí duas conclusões. Em primeiro lugar há nos criminosos uma suscetibilidade desmedida, ${ }^{40}$ uma timidez, um egoísmo - que são atributos, como

39. Foi o que Garofalo, apesar de dominado pela noção da obtusão do senso moral, reconheceu para um ou outro caso. "É verdade, diz ele, que a ausência do senso moral nem sempre basta para explicar certos crimes. Vem juntar-se a ela um amor-próprio exagerado que faz sentir mais vivamente um dano suposto ou mesmo insignificante. É assim que um certo T..., incomodado porque o seu criado o houvesse deixado, armou-lhe uma emboscada e o matou com um tiro de fuzil. A conduta desse desgraçado, que não teria senão ligeiramente vexado um outro patrão, tinha sido para ele uma afronta que exigia uma vingança sangrenta! Diz-se, em semelhante caso, que há desproporção entre a causa e o efeito. Esta expressão é filosoficamente absurda; a proporção não pode senão existir sempre. É que a causa não é unicamente aquela que se acredita conhecer, e que teria sido insuficiente”... (La Criminologie, par le Baron R. Garofalo. 5.e édition entièrement refondue et augmentée. Paris: Alcan, 1905, p. 111). - Por seu turno Tuozzi, tratando do primeiro requisito exigido para que se justifique a ação em estado de necessidade - a certeza do mal que o agente quer evitar - observa que esse requisito "deve ser apreciado, não na sua realidade objetiva, mas subjetivamente, em relação ao estado de ânimo em que se acha, no momento do fato, aquele que invoca a justificativa” (Galdino Siqueira, op. cit., 437).

40. “... encontra-se, demais, a falta de senso moral com amor-próprio exagerado, a vaidade moderada, a suscetibilidade excessiva, caracteres que se encontram tão freqüentemente, como vimos, entre os criminosos.” (Garofalo, loc. cit.). 
será demonstrado, de um verdadeiro exagero da personalidade. Em segundo lugar, vê-se que o instinto de conservação procura realizar-se neles de modo inadequado, porque excessivo. Este excesso é a própria desproporção entre o móvel e o ato. - $\mathrm{O}$ exagero é o atributo do criminoso; o excesso o do crime.

O problema, para ser convenientemente debatido, exige que partamos da psicologia do homem primitivo. Este, enquanto vive em horda, não encontra nenhum limite à satisfação dos seus desejos. A morte do semelhante é uma solução não cruel da luta pela existência. Com a noção do crime ela se torna arriscada. É natural que o homem procure evitá-la sistematicamente. Imprime-se a grande corrente nesse sentido. É preciso uma força superior a essa tendência para condicionar o crime. Esta força deveria ser procurada nas condições anteriores do grupo social. Os que matam, com efeito, são reacionários, indivíduos que restauram o antigo estado. Não o fazem, porém, senão acossados pela necessidade, real ou imaginária.

Camerano, norteado já por um critério rigorosamente biologista, pôs a condição maior da antinaturalidade, ao estudar o delito entre os animais, naqueles atos que ou constituam uma contravenção direta às leis que presidem à conservação do indivíduo e à da espécie, ou então que prejudiquem os outros animais, sem serem necessários à conservação do indivíduo ou a da espécie. ${ }^{41}$

Nada mais do que com os elementos da experiência, formuláramos uma definição, se não semelhante à do autor do Delito entre os animais, ao menos colateral, por isso que igualmente evolucionista, sustentando que o crime resulta de um modo particular do indivíduo apresentar-se na luta pela vida. É exato que - digamo-lo desde já - não chegamos à definição do crime senão pelo interesse de interpretar-lhe o mecanismo, - coisa, aliás, de que o criminologista italiano naturalmente não cuida, e de que a nossa tese faz a sua preocupação nuclear.

Examinando detidamente os dois pontos de vista, observa-se que há, de resto, uma grande diferença entre o conceito de Camerano e o nosso. Para esse autor, os atos dividem-se em duas categorias: os que provêm à conservação do indivíduo e à da espécie e os que atentam contra as suas leis, - aos últimos dos quais confere ele o caráter de delituosos.

$\mathrm{Na}$ nossa concepção, entretanto, essa distinção não existe. O homem, no nosso entender, bem como o animal, não se lança originariamente na prática de um ato que atente contra as leis da conservação do semelhante. É, ao contrário, na realização mesma de parte desse instinto, que ele comete a delinqüência. E isso porque não dosou bem a energia a empregar, caindo num excesso, que é, para nós, o que caracteriza o crime. 
Em rigor podia-se dizer que o animal, pelo menos no nosso conceito, não vê jamais a figura daquele contra quem atenta, mas tão-somente a sua, como igualmente não pesa o dano que causa a outrem, mas o próprio benefício, não sendo realmente senão este último o exclusivo móvel do seu ato.

Inicialmente, pois, ele procura exercer apenas a parte que lhe cabe na defesa da espécie, pela conservação precípua de si próprio. Não sabendo medir exatamente a força a aplicar na efetivação desse ato, em princípio legítimo, precipita-se numa prática delituosa.

Não se pode igualmente estabelecer comparação entre a nossa definição e a de Ingenieros: "O delito é uma transgressão das limitações impostas pela sociedade ao indivíduo na luta pela existência. Lesiona direta ou indiretamente o alheio direito à vida, cujas condições são estabelecidas pela ética social e tendem a fixar-se em fórmulas jurídicas, variáveis segundo as circunstâncias de tempo, meio e lugar". ${ }^{42}$

Esta definição tem de comum com a nossa apenas a forma. No fundo, ela nada mais representa do que a velha noção jurídica, tão malsinada pelos seus defeitos, segundo a qual o delito é toda violação da lei penal. Na definição de Ingenieros, parte-se igualmente de uma lei estabelecida, determinando a medida que o homem deve agir na obtenção dos meios de existência, em seu sentido mais amplo; o delito virá da "transgressão" dessas "limitações”, duma infração à lei primeiro consuetudinária ("ética social”), depois estatutária ("tendente a fixarse em fórmulas jurídicas”). Repitamos, porém, mais uma vez, que a nossa definição só vale em função da psicologia do delinqüente, que a explica. Nada seria de fato esse excesso material, sem o competente exagero psíquico que o condiciona.

É certo que a forma desmesurada com que o indivíduo procura realizar a luta pela existência não se torna criminosa em todos os casos, mas tão-somente quando exercida contra o semelhante, embora esse mesmo excesso praticado pelo homem, por exemplo, contra os animais, desperte logo uma revolta que, se não vai a ponto de lhe motivar punição, é bastante para caracterizar o ato como uma crueldade.

Cabe, pois, aqui, associar ao conceito evolucionista que defendemos, a concepção da escola antropológica, quando procura o caráter de antinaturalidade, o caráter criminoso, na “de um animal da parte de um animal da mesma espécie”* (Ferri).

42. José Ingenieros. Criminologia. 6a edición, corregida por el autor. Buenos Aires: Rosso, 1916. p. 26.

* A citação de Dyonélio diz: "uccisione di um animale da parte di um animale della stessa specie” (N. do R.). 
Diremos, portanto, que o delito, em particular o assassínio, nada mais é do que a resultante, contra o semelhante, do excesso que o homem põe na realização da luta pela vida.

Este é o plano geral do presente trabalho. Cada um dos pontos aqui ligeiramente discutidos será tratado com um desenvolvimento proporcional à sua importância. A situação moral e material do homem primitivo (concebido, aliás, em grande parte através do selvagem moderno); os seus meios de existência; o gradual aparecimento, no seu espírito, de uma noção tendente a separar as ações em dois grupos: as permitidas e as ilícitas; o horror ao crime, de que os sistemas tabus nos dão uma imagem ao mesmo tempo nítida e terrificante, e os principais problemas psicológicos que esses fatos envolvem, serão objeto dos dois primeiros capítulos, parte preliminar, acessória, mas indispensável.

No terceiro capítulo inicia-se a parte verdadeiramente médica deste estudo. Partindo da psicologia do delinqüente, concebida, todavia num plano novo, procuramos chegar a uma síntese caracterológica que nos facilite a decifração psicopatológica do crime, sonho eternamente alimentado pela ciência, embora sujeito às alternativas duma fortuna vária, nem sempre feliz...

Feita, pois, como já está, a delimitação da questão com o estudo, embora sumário, do homicídio e o seu conceito através da evolução natural do crime, a restante matéria aqui tratada pode resumir-se neste esquema: $1^{\circ}$ ) o homem primitivo e o selvagem moderno - suas necessidades: procura do alimento e do abrigo, necessidades sexuais; $2^{\circ}$ ) noção da criminalidade, em que é posto sucessivamente em destaque o regime da licença plena, a primeira limitação ao arbítrio como movimento reflexo, a punição tabu e o seu alcance em criminologia; $3^{\circ}$ ) psicologia do delinqüente - ensaio de caracterologia, com os parágrafos: a) aptidão possessiva, b) ideal da perfeição, inflexibilidade psíquica, exagero da personalidade, c) o mundo como fórmula simples, o delinqüente e o seu logicismo, d) timidez, insegurança, certo grau de impulsividade; $4^{\circ}$ ) temperamento criminal (apreciação geral dos temperamentos em medicina e do temperamento criminal em face da noção moderna do temperamento psicopatológico); 5º estados prépsicóticos, em suas relações com o temperamento criminal, ou seja: discussão sobre a existência de uma "psicose criminal”, estados pré-psicóticos propriamente ditos, a questão das “constituições” em patologia mental; $6^{\circ}$ ) o temperamento criminal e a sua posição nosográfica; $7^{\circ}$ ) finalmente, as nossas conclusões. 